\title{
Influence of the Material Properties on Microgrooving using Wire Tools Electrodeposited with Diamond Grains
}

\author{
Masaya Gemma, Jiayu Liu, Satoshi Sakamoto
}

\begin{abstract}
In this study, the main objective is to clarify the relationship between the material properties of the work material and the grooving properties for various work materials from hard and brittle materials to metallic materials. In this paper, in order to investigate the grinding characteristics of diamond electroplated wire tools, including the wear characteristics, we conducted grooving experiments with borosilicate glass (Pyrex), which is a kind of hard and brittle material, and aluminum alloy (A5052), and tough pitch copper (C1100), a kind of metallic material, using diamond electroplated wire tools in a work material rotation method. As a result of the grooving experiments, it was clarified that the grooving characteristics of the work materials were influenced by the hardness and brittle behavior of the materials. The groove depth is influenced by the hardness and brittleness behavior of the material. When machining hard materials, the groove depth increases slowly in the initial stage of machining due to the poor bite of the wire tool, but increases rapidly as the machining progresses. On the other hand, the groove width does not depend on the machining time or speed, but is influenced by the hardness of the material and the ease with which plastic deformation occurs. The wear of the wire tool is also influenced by the hardness and brittleness of the material. In the machining of hard materials, the wear caused by stray wire and vibration in the early stages of machining was significant. The grinding ratio calculated from the ratio of the groove depth to the amount of grinding has a very different trend for hard and brittle materials and metallic materials. In the machining of hard and brittle materials, the amount of machining increased rapidly as machining progressed, so the grinding ratio also increased, but in metallic materials, the amount of machining itself was small and the grinding ratio did not increase. For A5052, the grinding ratio tended to decrease as machining progressed. Future work In the future, it is necessary to clarify the machining conditions to reduce the wear caused by stray wire tools and vibration during the initial machining of hard materials.
\end{abstract}

Keywords: Grooving Characteristics, Hard and Brittle Materials, Metal Materials, Material Properties, Wire Tools.

\section{INTRODUCTION}

$\mathrm{P}_{\text {olycrystalline silicon and single crystalline silicon are }}$

Manuscript received on October 07, 2021.

Revised Manuscript received on October 13, 2021.

Manuscript published on October 30, 2021.

* Correspondence Author

Masaya Gemma*, Department of Technology Education, Keio Futsubu School, Yokohama, Japan. Email: masaya-pw@keio.jp

Jiayu Liu, Department of Semiconductor, TDI Product Solution Company, Yokohama, Japan. Email: liujiayu0404aa@163.com

Satoshi Sakamoto, College of Education, Yokohama National University, Yokohama, Japan. Email: sakamoto-satoshi-tv@ynu.ac.jp

(C) The Authors. Published by Blue Eyes Intelligence Engineering and Sciences Publication (BEIESP). This is an open access article under the CC BY-NC-ND license (http://creativecommons.org/licenses/by-nc-nd/4.0/) widely used as semiconductor materials in various electronic devices. In recent years, silicon carbide ( $\mathrm{SiC}$ ) has been used as a power semiconductor to control the power supply [1]. Sapphire is also widely used for optical components [2]. These materials such as silicon or Sapphire have high hardness but are brittle and also difficult to cut. Recently, the mainstream method for cutting $\mathrm{Si}$ wafers used as semiconductor substrate materials from ingots is slicing with a multi-wire saw [3] as shown in Fig. 1, which cuts the work material by pressing it against a wire tool that is wound around multiple guide rollers rotating at high speed while applying processing fluid.

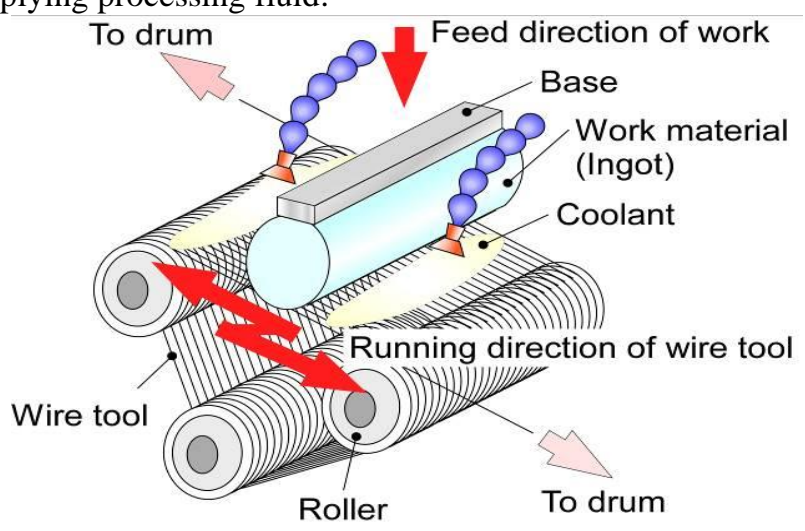

Fig. 1. Schematic diagram of a multi-wire saw

The slicing method using a multi-wire saw can be mainly divided into the free abrasive method using a wire tool and slurry as cutting tools and the fixed abrasive method using a fixed abrasive wire tool as cutting tools [4]. Cutting by the fixed abrasive method has excellent processing efficiency and cutting processing can be performed in a short time. On the other hand, although the cutting efficiency of the free abrasive method is inferior to that of the fixed abrasive method, the surface finish is excellent and high-precision machining can be performed. In the cutting of hard and brittle materials, in addition to the high cutting efficiency of the fixed abrasive method, the fixed abrasive method is often used because of the poor working environment caused by the slurry used in free abrasive method, difficulty in cleaning the work material, and waste slurry [5]. In the case of thin slicing of hard and brittle materials, the propagation of microcracks, such as cracks and chips, in the work material during machining may greatly influence the machining efficiency and accuracy [6], and their suppression is one of the most important issues in achieving high precision slicing. 
To solve this problem, wire tools that suppress the occurrence of microcracks as much as possible have been proposed [7], but the material properties and processing characteristics, such as under what conditions microcracks occur, have not been clarified. We have been conducting research related to these issues. We have investigated the relationship between the machining conditions and the properties of the work material by comparing hard and brittle materials with materials which have different properties, and machining them with diamond electroplated wire tools [8]. In this research, the main purpose is to investigate the relationship between the material properties of the work material and the grooving characteristics for work materials such as hard and brittle materials and metal materials. In this paper, we report the results of precision grooving experiments using hard and brittle materials and metallic materials to investigate the machining characteristics and tool wear of diamond electrodeposited wire tools.

\section{EXPERIMENTAL PROCEDURE}

\section{A. Experimental equipment and machining conditions}

Table I shows the dimensions and strength of the diamond electroplated wire tools used in this study. Fig. 2 shows the appearance of the unused diamond electroplated wire tool. The core wire diameter is $200 \mu \mathrm{m}$, and the outermost diameter is $265 \mu \mathrm{m}$. The breaking strength (load) of the diamond electrodeposited wire tool used in this study is 105 $\mathrm{N}$. However, because only a part of the wire tool is used heavily in the experiments in this study, there is a concern about wire breakage and excessive wear of the wire tool. Therefore, the tension applied to the wire tool in this study was set to be as low as $8.5 \mathrm{~N}$ for the experiment.

Fig. 3 shows a simple schematic diagram of the experimental setup, which is a modified tabletop CNC milling machine. The work material is fixed to the spindle (Z-axis) via a work holder, and rotational motion is applied. In this study, the relative velocity between the wire tool and the work material is generated by the rotation of the work material, and precision grooving experiments are conducted. In addition, the $\mathrm{X}-\mathrm{Y}$ table, on which the wire tool is fixed at a constant tension, reciprocates in the $\mathrm{X}$-axis direction to enable a longer wire tool length to be contributed to the machining ( $80 \mathrm{~mm}$ in this study).

Fig. 4 shows the machining schematic diagram when viewed from the $\mathrm{Z}$-axis direction. The wire tool is pressed against the work material $5 \mathrm{~mm}$ beforehand, and no feed in the $\mathrm{Y}$-axis direction is performed in this experiment.

Table II shows the materials used in the experiment and the main conditions. The work materials were borosilicate glass (Pyrex), aluminum alloy (A5052), and tough pitch copper (C1100) all with a diameter of $10 \mathrm{~mm}$. The temper of the metal materials used in this study is H34 for A5052 and $\mathrm{H}$ for C1100. The rotational speed of the work material was set to three levels: $420 \mathrm{~m} / \mathrm{min}, 770 \mathrm{~m} / \mathrm{min}$, and $1350 \mathrm{~m} / \mathrm{min}$.

A solution-type water-soluble machining fluid was used as the machining fluid. A $10 \mathrm{~mL} / \mathrm{min}$ supply was intensively applied to the machining area. The $\mathrm{X}$-axis moving distance of the electrodeposited diamond wire tool was set at $80 \mathrm{~mm}$.

The X-Y table feed rate was set at $1000 \mathrm{~mm} / \mathrm{min}$ for the experiment. The maximum machining time was 25 minutes for the experiment on the influence of machining time, and each measurement was carried out at 5 minutes intervals. In all other experiments, the machining time was set to 15 minutes.

Table- I: Dimensions and strength of the diamond electroplated wire tools used in this study

\begin{tabular}{cc}
\hline \multicolumn{2}{c}{ Wire tools } \\
\hline Abrasives & Diamond grain \\
Particle size & $30-40[\mu \mathrm{m}]$ \\
Material of core & SWRS82A $(\mathrm{JIS} \mathrm{G} 3502)$ \\
Core diameter & $200[\mu \mathrm{m}]$ \\
Outer diameter & $265[\mu \mathrm{m}]$ \\
Braking strength & $105[\mathrm{~N}]$ \\
Tension & $8.5[\mathrm{~N}]$ \\
\hline
\end{tabular}

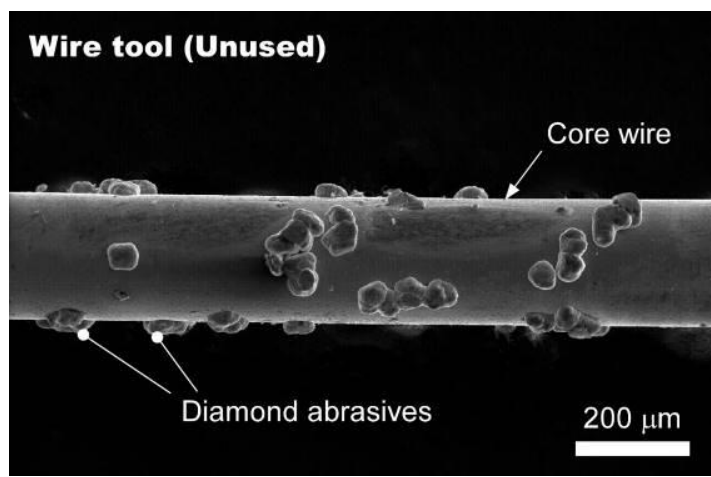

Fig. 2.Appearance of the unused diamond electroplated

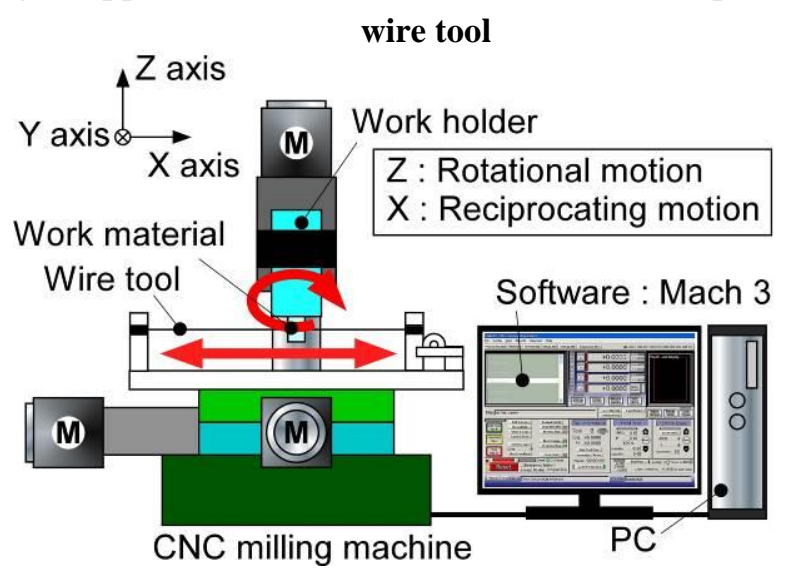

Fig. 3.Schematic diagram of the experimental setup

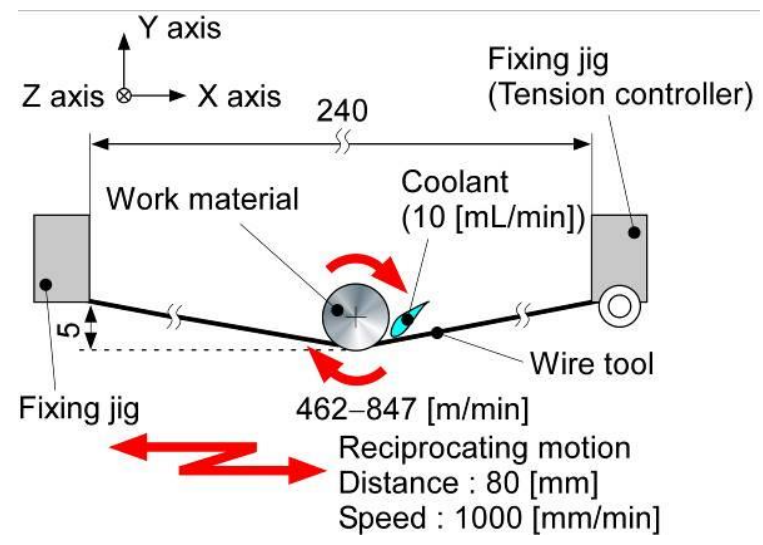

Fig. 4.Machining schematic diagram

Published By:

Blue Eyes Intelligence Engineering and Sciences Publication (BEIESP)

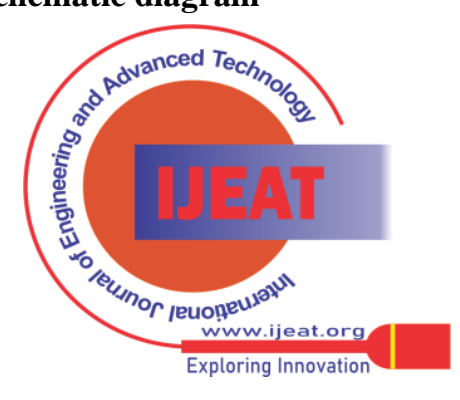


Table- II: Materials used in the experiment and the main conditions

\begin{tabular}{|c|c|}
\hline \multicolumn{2}{|c|}{ Work material } \\
\hline Material & Pyrex, A5052 H34, C1100 H \\
\hline Diameter & $10[\mathrm{~mm}]$ \\
\hline Rotational speed & $420,770,1350[\mathrm{~m} / \mathrm{min}]$ \\
\hline \multicolumn{2}{|c|}{ Working fluid } \\
\hline Coolant & Water-soluble (Solution type) \\
\hline Supply amount & $10[\mathrm{~mL} / \mathrm{min}]$ \\
\hline \multicolumn{2}{|c|}{$\mathrm{X}-\mathrm{Y}$ table } \\
\hline $\mathrm{X}$ axis travel distance & $80[\mathrm{~mm}]$ \\
\hline Moving speed & $1000[\mathrm{~mm} / \mathrm{min}]$ \\
\hline Machining time & 15,25 [min] \\
\hline
\end{tabular}

\section{B. Definition of abrasive grain wear}

Fig. 5 shows the definition of abrasive grain wear in this study. The amount of wear in this study was defined as the amount of decrease in the height of diamond grains electrodeposited on the wire tool, which was obtained from the height of the grains when not in use by measuring the distance from the surface of the core wire using SEM (SEM : Scanning Electron Microscope). The measurement range (distance) was set at $1.2 \mathrm{~mm}$ (for about 32 abrasive grains), although it was a small range of the portion that contributed to the machining.

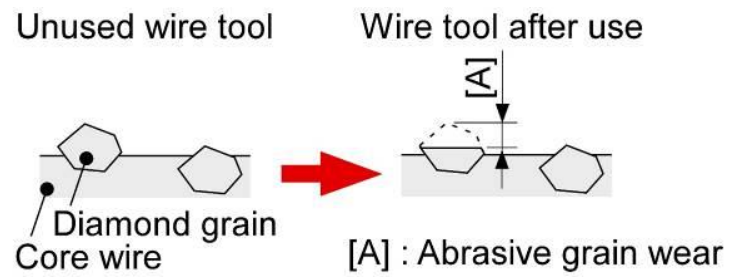

Abrasive grain wear

$=($ Outermost diameter - Wire diameter after use $) / 2$

Fig. 5.Definition of abrasive grain wear in this study

\section{The Concept of Grinding Ratio in this Study}

The grinding ratio is generally defined as the ratio of the amount of removal to the amount of polishing, but in this study, it is defined approximately as the ratio of the groove depth to the amount of polishing. It is possible to judge the machining condition by the size of the grinding ratio.

For example, the larger the grinding ratio, the better the machining performance can be judged. On the other hand, the smaller the grinding ratio is, the lower the machining performance is considered to be.

It should be noted that the dimension of the value to be obtained is different because the general grinding ratio is obtained by the ratio using the volume of removal, while the grinding ratio defined in this study is obtained by the ratio using the length of the groove depth. Since the grinding ratios in this study are approximations, while they can be compared among the materials in this study, they cannot be compared with general grinding ratios.

\section{PHYSICAL PROPERTIES OF WORK MATERIALS}

Table III shows the hardness and elastic modulus of the work materials. The Vickers hardness of Pyrex in Table III is a reference value converted from Knoop hardness by using the hardness conversion table shown in ASTM E140 [9].
Hardness is higher for Pyrex, C1100, and A5052, in that order. The elastic modulus is higher for C1100, A5052, and Pyrex, in that order. In general, the harder a material is, the less likely it is to undergo plastic deformation and the more likely it is to exhibit brittle behavior. Pyrex is the hardest of all the work materials, and it can be said that it is a material that behaves with relatively brittle fracture.

Table- III: Hardness and elastic modulus of the work materials [10]-[12]

\begin{tabular}{cccc}
\hline Work material & Pyrex & A5052 H34 & C1100 H \\
& {$[10]$} & {$[11]$} & {$[12]$} \\
Vickers Hardness [HV] & $404^{*}$ & 68 & $90-105$ \\
Elastic Modulus [GPa] & 63 & 70 & 118 \\
\hline * Converted from Knoop Hardness Value & &
\end{tabular}

\section{EXPERIMENTAL RESULTS AND DISCUSSION}

\section{A. Wire tool and work material after grooving}

Fig. 6 shows an example of the appearance of a diamond electrodeposited wire tool that grooved for 25 minutes using an A5052 as the work material. The results were obtained when the rotational speed of the work material was set to 420 $\mathrm{m} / \mathrm{min}$. From the Fig. 6, Although there were some damages such as scratch marks on a part of the core wire caused by the progress of machining, there was no serious wear of the abrasive grains, and it is thought that the machining performance was maintained. Fig. 7 shows an example of a cut groove of Pyrex. It can be seen that the machining of Pyrex, which is a hard and brittle material, causes straying marks of wire tool and chipping of the groove edge in the initial stages of machining.

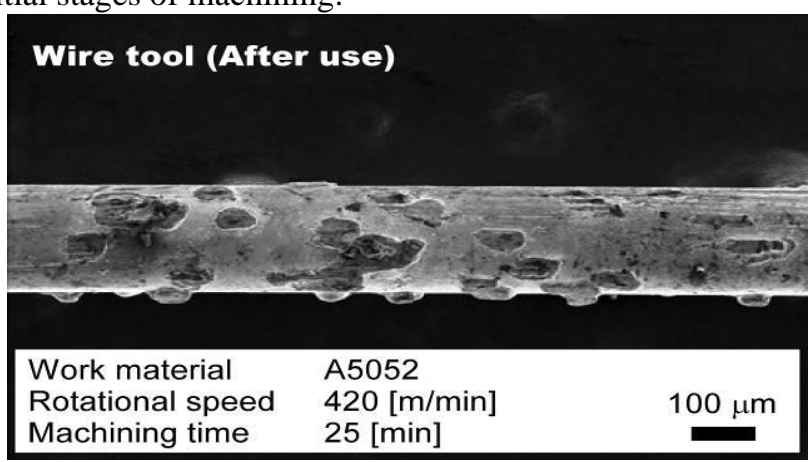

Fig. 6.An example of the appearance of a wire tool after grooving A5052

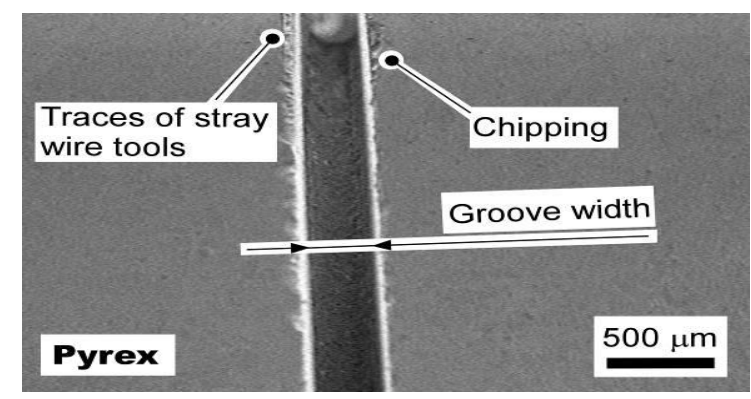

Fig. 7.An example of a cut groove (Pyrex)

Published By:

Blue Eyes Intelligence Engineering and Sciences Publication (BEIESP)

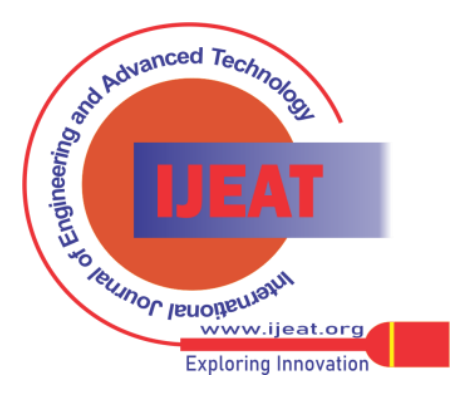




\section{B. Influence of machining time}

Fig. 8 shows the relationship between machining time and groove depth. The rotational speed of the work material is constant at $420 \mathrm{~m} / \mathrm{min}$. From Fig. 8, it can be seen that the groove depth tends to increase with the machining time. Particularly in the machining of Pyrex, the cutting performance of the diamond electrodeposited wire tool is high, and also slightly improved with the passage of machining time. Pyrex has a high hardness, but is prone to brittle fracture by machining, which is considered to have increased the amount of machining. In addition, it is considered that the rapid increase in the machining amount with the progress of machining is due to the poor bite of abrasive grains in the initial stage of machining because of the high hardness of Pyrex, which was improved as the machining progressed. On the other hand, in the machining of A5052 and C1100 both as metallic materials, the groove depth increases. But compared with Pyrex, the groove depth is shallower, and the machining amount is smaller. Between A5052 and C1100, A5052 has better machinability, which is probably because A5052 has lower hardness. However, since A5052 is less prone to brittle fracture than Pyrex, it is considered that the machining amount of A5052 is lower than that of Pyrex. Particularly, the machinability was poor at C1100. This is probably caused by the properties of C1100, which is less prone to brittle fracture than Pyrex and has a higher hardness than A5052 when compared with the three types of work material materials.

Considering the damage to the wire tool, it can be confirmed that the machining performance of the wire tool is being maintained, as the machining amount continues to increase in the machining of all work materials.

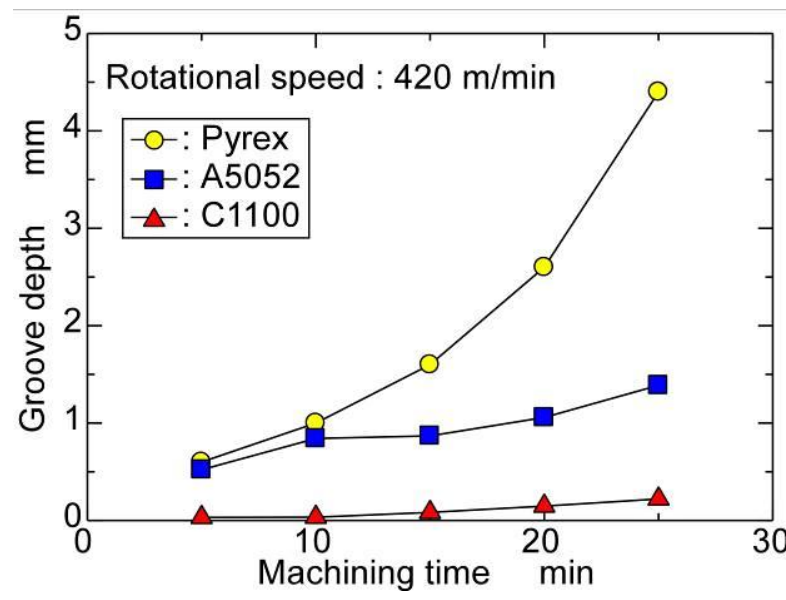

Fig. 8.Relationship between machining time and groove depth

Fig. 9 shows the relationship between machining time and abrasive grain wear. The rotational speed of the work material is constant at $420 \mathrm{~m} / \mathrm{min}$. It can be seen that the tool wear tends to progress with machining time in the machining of any work material, and a larger amount of wear was observed when machining C1100 compared to Pyrex with high hardness. Although Pyrex has a high hardness, the contact surface that causes damage to the abrasive grains is prone to brittle fracture, so abrasive grain wear is considered to have been low. C1100, in addition to being less prone to brittle fracture than Pyrex, has a higher hardness than A5052, so the damage to the abrasive grains is considered to have been high. In other words, in addition to the hardness of the material, brittle behavior is also thought to have an influence on abrasive grain wear.

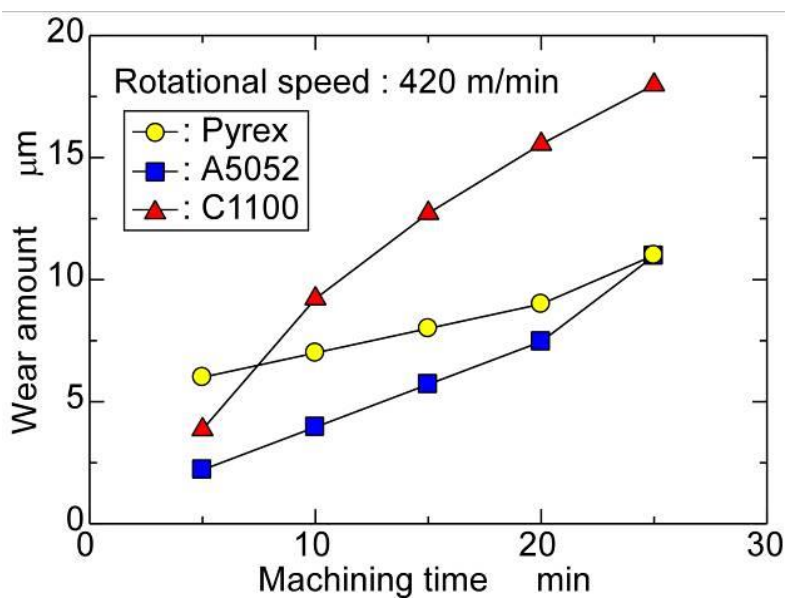

Fig. 9.Relationship between machining time and abrasive grain wear

Focusing on the machining of Pyrex, in the initial stage of machining, the abrasive grain wear increased significantly as the machining progressed, but after that, the increase became slower. This is considered to be due to the fact that, in the initial stage of machining, Pyrex is highly hard and abrasive grain wear increases, but after that, Pyrex has brittle fracture, and abrasive grain wear has become slower. As seen in Fig. 6 and Fig. 7, since the amount of machining increases with the passage of machining time, it can be considered that although diamond abrasive grains are wearing out in the range of this experiment, it has not caused significant loss of the abrasive grains themselves or large-scale damage to the core wire.

Fig. 10 shows the relationship between machining time and groove width. The dashed line in Fig. 10 shows the outermost diameter of the diamond electroplated wire tool used. In the case of machining with Pyrex, the diamond electrodeposited wire tool broke after 25 minutes, so the data for 25 minutes grooves were not available. In the case of machining with $\mathrm{C} 1100$, it was difficult to measure clear groove widths for machining times of 10 minutes or less, so the data for 15 minutes and later were used.

Fig. 10 shows that the groove widths of all the tools are wider than the outermost diameter of the diamond electrodeposited wire tool, and that the groove widths tend to increase in the order of Pyrex, A5052, and C1100. The groove width of each work material did not depend on the increase in processing time and was almost constant at all processing points. The groove width was $4.3 \%$ wider for Pyrex, 15.2\% wider for A5052, and 18.6\% wider for C1100 than the outermost diameter of the wire tool on average. Comparing the metal materials A5052 and C1100, the groove width of C1100 is slightly wider than that of A5052, but almost the same.

Published By:

Blue Eyes Intelligence Engineering and Sciences Publication (BEIESP) 
Pyrex with high hardness has a narrower groove width than the A5052 and C1100. This may be due to Pyrex being less susceptible to plastic deformation than A5052 and C1100, making it difficult for the groove width expansion to progress.

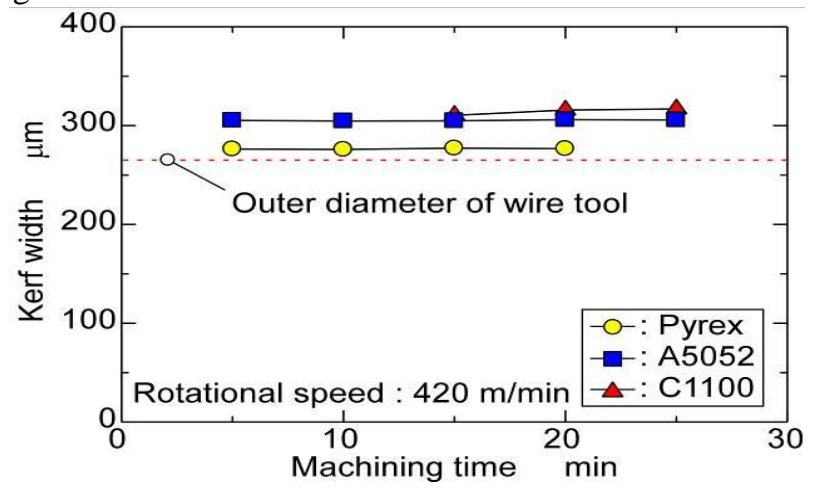

Fig. 10. Relationship between machining time and groove width

Fig. 11 shows the relationship between the machining time of the work material and the grinding ratio. The rotational speed of the work material is constant at $420 \mathrm{~m} / \mathrm{min}$. Fig. 11 shows that with the passage of machining time, the grinding ratio tends to decrease when A5052 is used as the work material, but increases in the case of Pyrex as the work material. In machining with high hardness materials, the abrasive grain wear is usually large, and the grinding ratio tends to decrease as the machining amount decreases because of the decrease in the machining performance of the wire tool. However, in the machining of Pyrex, the increase in the machining amount due to brittle fracture, more than the tool wear caused by machining, may have contributed to the increase in the grinding ratio. In addition, the tendency of the grinding ratio to increase as Pyrex is machined is influenced by the tremendous wear of the tool in the initial stage of machining caused by the high hardness of Pyrex. In other words, the tool wear in the initial stage of machining was large, and the grinding ratio in the initial stage of machining was low. And also, it is thought that the poor biting of abrasive grains into the work material and the large amount of wear in the initial stage of machining are influenced on the increase of grinding ratio. In other words, the grinding ratio increased as the machining progressed because the amount of machining increased by the micro fracture of Pyrex and the grinding ratio at initial stage of machining was low.

In the case of C1100 machining, the grinding ratio was also very low because the machining amount itself was small.

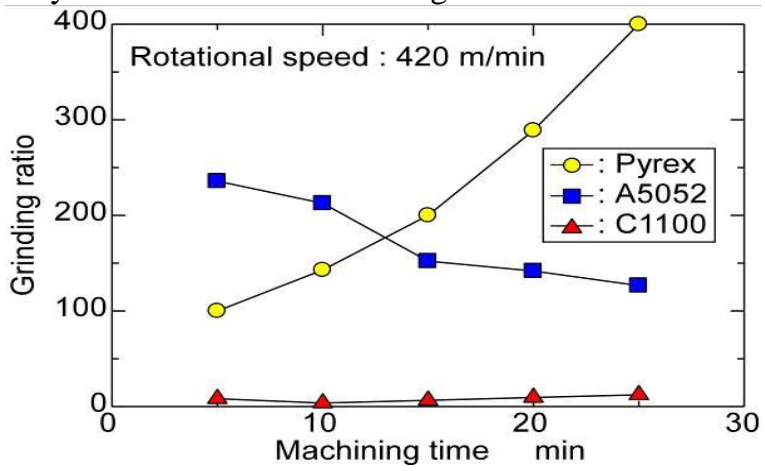

Fig. 11. Relationship between the machining time of the work material and the grinding ratio

\section{Influence of work material rotational speed}

Fig. 12 shows the relationship between the rotational speed of the work material and the groove depth. The machining time was kept constant for 15 minutes. Fig. 12 shows that the groove depth of Pyrex tends to become deeper as the rotational speed of the work material increases, while the groove depth of A5052 and C1100 is almost constant, independent of the rotational speed of the work material. Pyrex is prone to brittle fracture as machining progresses. As the rotational speed of the work material increased, the brittle fracture of Pyrex was accelerated, and the groove depth was considered to have increased. In other words, it can be said that in machining Pyrex, grooving proceeds by brittle machining. Metallic materials, on the other hand, are far less prone to brittle fracture than Pyrex. This means that the progression of groove machining in metallic materials is not brittle. This is thought to be the reason why the groove depth did not increase in the machining of A5052 and C1100 compared to Pyrex. In other words, the tendency of the groove depths for hard and brittle materials and metallic materials is quite different. Comparing A5052 and C1100, the groove depth of A5052 is increased. This may be influenced by the lower hardness of A5052 compared to C1100.

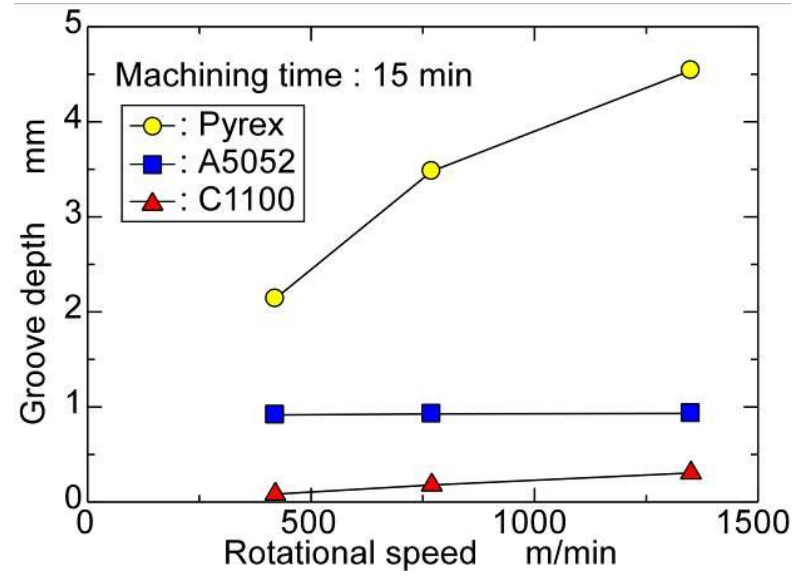

Fig. 12. Relationship between the rotational speed of the work material and the groove depth

Fig. 13 shows the relationship between the rotational speed of the work material and the amount of abrasive grain wear. The machining time is constant for 15 minutes. From Fig. 13, it can be seen that the amount of abrasive grain wear tends to increase as the rotational speed becomes higher, and the wear is more significant when Pyrex and C1100 are used as the work material. Comparing Pyrex and C1100, as can be seen from Fig. 12, the groove depth is deeper in Pyrex, while it is very shallow in C1100. In other words, abrasive grain wear in Pyrex is for cases where the amount of machining by abrasive grains is significantly increased, while abrasive grain wear in C1100 is for cases where the amount of machining by abrasive grains was not increased much. From this, it can be said that the machinability of $\mathrm{C} 1100$ is poor in this experiment. In the machining of Pyrex, the groove machining is brittle, and the damage to the abrasive grains is low for its high hardness. 
On the other hand, C1100 is considered to have accelerated abrasive grain wear because the groove machining progress is plastic, not brittle and the hardness is also higher than the same metal material, A5052. A5052 has relatively low hardness, and abrasive grain wear is considered to have been relatively low. Fig. 14 shows the relationship between the rotational speed of the work material and the groove width. In the case of the Pyrex, the diamond electrodeposited wire tool broke at $770 \mathrm{~m} / \mathrm{min}$, and data on the groove width after that was not available. From Fig. 14, it can be seen that the groove widths of all the tools are wider than the outermost diameter of the diamond electrodeposited wire tool, and that the groove widths tend to increase in the order of Pyrex, A5052, and C1100. This was the same trend as the relationship between machining time and groove width shown in Fig. 10. The groove width was $4.4 \%$ wider for Pyrex, $15.4 \%$ wider for A5052, and $18.3 \%$ wider for C1100 than the outermost diameter of the wire tool on average. The groove width does not depend on the rotational speed of the work material, and the groove width tends to be wider for metallic materials.

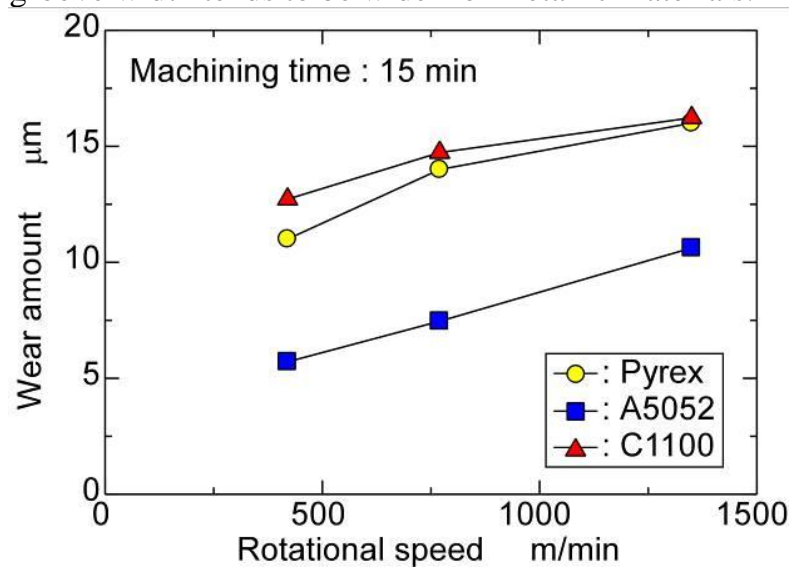

Fig. 13. Relationship between the rotational speed of the work material and the amount of abrasive grain wear

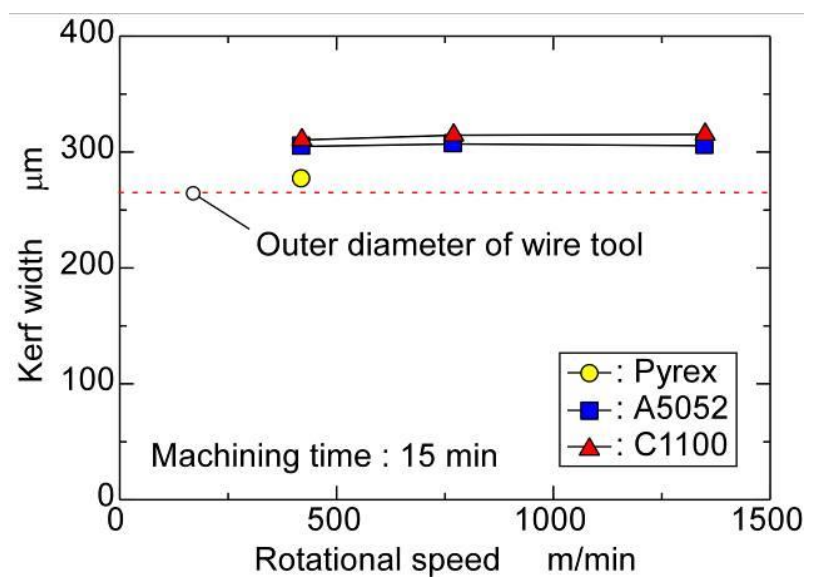

Fig. 14. Relationship between the rotational speed of the work material and the groove width

Fig. 15 shows the relationship between the rotational speed of the work material and the grinding ratio. The machining time was kept constant for 15 minutes. From Fig. 15, it can be seen that when Pyrex is the work material, the faster the rotational speed of the work material, the more the amount of machining increases rather than the amount of abrasive grain wear, and the grinding ratio tends to increase. This is thought to be caused by the brittle behavior of the work material. For the metallic materials A5052, the grinding ratio tended to decrease because the amount of machining did not depend on the rotational speed of the work material. In other words, although the abrasive grain wear increased with the rotation of the work material, the groove depth did not increase, so the grinding ratio tended to decrease. In particular, in the machining of C1100, the amount of machining was very less than the amount of grain wear, and the grinding ratio became a low value.

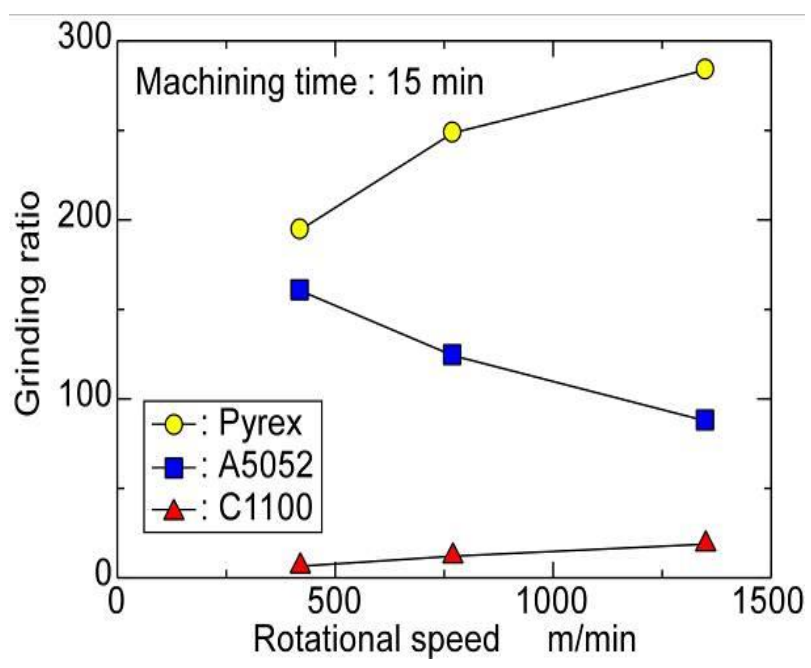

Fig. 15. Relationship between the rotational speed of the work material and the grinding ratio

\section{CONCLUSION}

In this study, we conducted precision grooving experiments using diamond electrodeposited wire tools with hard and brittle materials and metals as work materials and investigated the machining characteristics including wear of the wire tools. As a result of the grooving experiments and observation of the wire tools, the following points were clarified.

1) The groove depth increased as the machining time and speed increased, and was influenced by the hardness and brittle behavior of the material. Pyrex has high hardness, but due to brittle fracture caused by machining, the groove depth increased more than A5052 and C1100, which have lower hardness than Pyrex. However, in the machining of hard materials, the increase in groove depth was gradual in the initial stage of machining due to poor bite of the wire tool, but increased rapidly as the machining progressed.

2) The groove width is independent of the machining time and speed, and is influenced by the hardness of the material and the ease with which plastic deformation occurs.

3) The wear of the wire tool is influenced by the hardness and brittle behavior of the material as well as the groove depth. In the machining of hard materials, straying and vibration occurred in the early stages of machining, and wear tended to be greater.

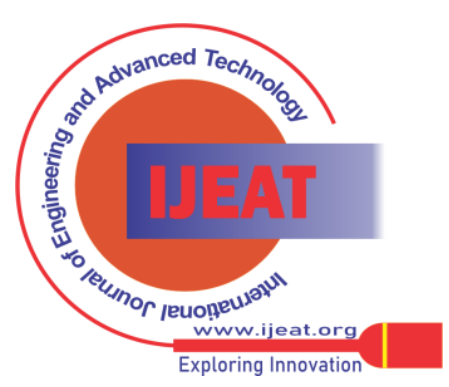


4) The grinding ratio tends to differ between hard and brittle materials and metallic materials. For hard and brittle materials, brittle fracture occurred as the machining time increased, and the groove depth increased rapidly, so the grinding ratio also increased. For the metallic material, the grinding ratio did not increase due to the lack of a significant increase in machining amount. For A5052, the grinding ratio decreased with the progress of machining.

\section{FUTURE PROSPECTS}

From the experimental results of Pyrex, it is clear that in the machining of hard and brittle materials, there are issues in terms of poor abrasive grain bite and abrasive grain wear in the initial stage of machining. In other words, by modifying the machining conditions in the initial stage of machining, there is a possibility that the machinability can be improved. For example, in this experiment, the machining speed was kept constant throughout the entire experiment, but in the machining of hard and brittle materials, it is thought to be effective to vary the machining speed in the initial stage of machining and gently accelerate it up to the maximum machining speed to reduce the damage to the abrasive grains in the initial stage of machining and at the same time to aim for the bite of the abrasive grains. Also, increasing the amount of machining fluid supplied to promote chip discharge and reduce friction on the machined surface can be considered as an effective method. It is necessary to investigate the machinability of hard and brittle materials with these improvements in the future.

\section{ACKNOWLEDGMENT}

We thank the Instrumental Analysis Center of Yokohama National University for their support and cooperation in carrying out this study. Additionally, part of this work was supported by JSPS KAKENHI Grant Number 16K06005.

\section{REFERENCES}

1. T. Susuki, T. Otsuki and J. Yan, "Precision slicing of single-crystal SiC using extremely fine fixed-abrasive diamond wire

," Transactions of the JSME (in Japanese), Vol. 84, No. 857, 2018, p. 17-00345.

2. T. Kato, "Development of Large SiC Wafer Processing Technique in "Novel Semiconductor Power Electronics Project Realizing Low Carbon Emission Society" Supported by NEDO," Journal of the Japan Society for Precision Engineering, Vol.80, No. 1,pp.18-22.

3. H. Wu, "Wire sawing technology: A state-of-the-art review," Precision Engineering, Vol.43, 2016, pp1-9.

4. H. Suwabe, H. Shirasu, M. Yoshikawa, H. Tokura and K. Ishikawa, "Development of Electrodeposited Endless Wire Tool of Diamond Grains Welding Method and Evaluation of Welding Point," Journal of the Japan Society of Precision Engineering, Vol.59, No.6, 1993, pp. 939-944.

5. Y. Tani, "Recent Trend of Abrasive Processing Technology." Journal of the Surface Finishing Society of Japan, Vol.49, No.9, 1998, pp. 928-932.

6. S. Sakamoto, M. Gemma, K. Hayashi, Y. Kondo, K. Yamaguchi, M. Yamaguchi and T. Fujita, "Influence of the Brittle Behavior of Work Materials on Microgrooving," Key Engineering Materials, Vol.703, No.17, 2016, pp.17-21.

7. H. Suwabe, A. Uratsuka, T. Ueno, T. Hattori, and K. Ishikawa, "Study on mirror slicing using resin-coted wire," Journal of the Japan Society of Precision Engineering, Vol 55, No.12, 2011, pp. 733-738.

8. S. Sakamoto, M. Gemma, Y. Kondo, K. Yamaguchi, M. Yamaguchi and T. Yakou, " Influence of the Characteristics of a Workpiece on the Slicing Characteristics Including Tool Wear," MATEC Web of Conferences, Vol.221, 2018, p. 04005.
9. ASTM International, "Standard Hardness Conversion Tables for Metals Relationship Among Brinell Hardness, Vickers Hardness, Rockwell Hardness, Superficial Hardness, Knoop Hardness, Scleroscope Hardness, and Leeb Hardness," ASTM E140, 12B, 2019.

10. MatWeb, LLC. (2021, 9, 30). Corning Pyrex ${ }^{\circledR} 7740$ Borosilicate Glass.

Available: http://www.matweb.com/search/DataSheet.aspx?MatGUID=5bb651 ca58524e79a503011b2cd8083d\&ckck=1

11. MatWeb, LLC. (2021, 9, 30). Aluminum 5052-H34. Available: http://www.matweb.com/search/DataSheet.aspx?MatGUID=8644ac8 8ccb647869449d6ff6ddfbaed

12. Mitsubishi Materials Corp. (2021, 9, 30). Oxygen-free copper, tough pitch copper, phosphorus deoxidized copper. Available:

13. https://www.mitsubishi-copper.com/jp/products/materials/cu/

\section{AUTHORS PROFILE}

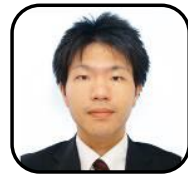

Education.
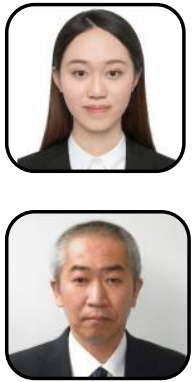

Masaya Gemma, received his master's degree from Yokohama National University, Japan in 2019. Now he is a teacher of technology education at Keio Futsubu School. His research interests include technology education and machining hard and brittle materials. He is a member of The Japan Society for Technology engineers, and the Japan society for abrasive technology.

Jiayu Liu, comes from China. She received the master' degree in 2021 from Yokohama National University. Her current position is an employee of TDI Product Solution Company. She is currently working on the quality test of semiconductor products.

Satoshi Sakamoto, received his doctorate from Kanazawa University, Japan in 1997. Now he is a professor at Yokohama National University. His current research interests include precision machining of hard and brittle materials. He is a member of the Japan society for precision engineering, the Japan society of mechanical

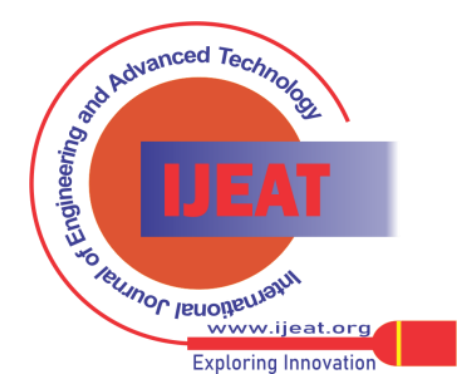

